\title{
ELT Teachers’ Role Within E-Learning and Communicative Teaching from Students’ Perceptions
}

\author{
Jie Xie, Genlin Zhang \\ School of Language, Literature and Law, Xi'an University of Architecture and Technology, Xi'an,China \\ Email: Jasminexie@sina.com, Zhanggenlin@gmail.com
}

Received 2012

\begin{abstract}
The present thesis aims to empirically determine the effects of technology, specifically the integration of e-learning within English language teaching, on students' perception of teachers' role. Participants were divided into experimental (e-learning) E-group and controlled (traditional) T-group. SPSS was used to analyze the data collected. The results show that, in both groups, students' perceptions of the teachers' role remain positive form the beginning of the term to the end. Such findings reveal that the role of ELT teachers within e-learning is analogous to an interactive teacher of the earlier conventions, a multifaceted one with strategy-oriented tasks ranging from Facilitation, Advising, Conducting experiments, Engineering activities, to Supporting divergent learning styles, pathways and creative productions (FACES). However, in the aspects of giving advice, offering educational and technological support and engineering various activities, e-learning group of students holds more positive attitude than the traditional group.
\end{abstract}

Keywords: Students’ Perception; Teachers’ Role; E-learning; Communicative Teaching

\section{Introduction}

The influence of technology in education is a widespread phenomenon. Within English Language Teaching, the rapid development of Information and Communication Technology (ICT) prompts changes in the ways and methods of teaching and preparing students for continuous learning and effective use of the language to communication with people from various parts of the globe. Now with multimedia computers and Internet resources available to common people, e-learning presents foreign language teaching and learning with unprecedented opportunities as well as challenges. E-learning applications in academies and institutes have long held scholars' attention throughout the world.

With the promotion of technological development, researches into constructivism have had an enormous influence on the study of English teaching. Meanwhile, the schools of constructivism-trivial constructivism, radical constructivism, social constructivism, and so on, have the common ground that knowledge is actively constructed by the learners and students acquire knowledge through interaction[4]. According to the constructivist theory, teachers should help students create knowledge by every means instead of imparting knowledge to them. So it is very significant for us teachers to determine the role of college English teachers and its function so that we can improve students' English achievements and their learning ability.

Compared with the college English syllabus, we must realize college students' English level is not optimistic. On the one hand, many students lack the ability of listening, or speaking, or reading, or writing, or translating. Although they have learned English for so many years, they can't express their ideas correctly in English. Lacking abilities of thinking and autonomous learning, they wholly rely on their teachers, believing their teachers stand for the only owner of knowledge. On the other hand, college English teachers mainly adopt the teacher- centered teaching approach in class, which failed to bring up students with initiative and creative power. They care little about students, neglect their needs and ignore the function of emotional factors in English teaching.

Gathering data from students, the present study intends to gather quantitative information about the teachers' role within e-learning, in order to fully understand how to synchronize and synergize the power of ICT tools within language learning and the learners' positive perception of these tools. Specifically, the study gathers students' perception about the teacher's strategies within e-learning and investigates whether technology changes forms of teaching and consequently, the teachers' role.

With the use of e-learning, a component of the $\mathrm{e}+\mathrm{c}$ framework of teaching English that employs digitalized materials and ICT-based support inside and outside the classroom, in order to enhance and practice autonomy among foreign language learners, the present study seeks to gather information to the following query: (1) Does e-learning change students' perception of teachers' role ? (2) What teaching strategies are acceptable within e-learning?

\section{Methodology}

\section{Participants}

The participants in this study are 385 freshmen enrolled in the 4-year program at the Xi'an University of Architecture and Technology from whom the data were collected during the 2009-2010 school year. They are selected randomly from 14 classes in 8 colleges and are assumed to represent a group of students in China who have had approximately ten years of formal English learning, receiving training and education for technically-oriented jobs.

\section{Instrument}

The Assessment of Teachers' role with E-Learning (ATREL 
$=18$ items) is a specially designed instrument to measure learners' perception of the teachers' role within e-learning. It contains items that reveal teacher's actions that are highly observable and thus, measurable. The instrument includes questions that gather demographic information such as their age, family background, learning experience.

The scoring is based on the 5-point scale that employs the following degrees of frequency: always (5), often (4), average (3), sometimes (2), never (1), where the number corresponds to the points attached to it. The higher the number, the more frequent the recurrence of the teacher's actions.

The conceptual framework that guided the development of the 18 items of the assessment is derived from the principles of task-based learning (Breen 157-174[5]; Willis 90-95[6]) that foments the directive role that teachers may assume to create effective learning opportunities "even within a predominantly learner-centered classroom” (Brown 115)[7]. Specifically, drawing from the notion of facilitation that states that it is a method of guiding and aiding through adjustment and regulation of interaction (Zimmerman and Evans 43-45), one understands the importance of pointing to an objective in order for the first move from the student to be possible[8]. From this standpoint, the instrument includes items that assess teacher's facilitative acts such as, explaining the rationale of activities, inclusive of e-learning, and the teachers' role as a guide in completing learning tasks ( ATREL item 3, 16,17).

Task-based learning is compatible with autonomy within foreign language learning (Littlewood 43-427) and inherently stipulates teacher's facilitation from the beginning to the final stage of a learning task[9]. In line with this, the instrument assesses teacher's counseling acts such as, attending to individual needs (ATREL item 8), relating to students in a friendly manner (ATREL item 10), giving praises to learning achievements (ATREL item 12), which facilitate dialoguing and continuous flow of advice. Also, it assesses the teachers' role of and engineer of activities and conductor of assessments who gather information about learner's learning processes and outcome, subsequent to constructing activities based on the principles of fun and interesting learning (ATREL item 5), interactive and cooperative learning (ATREL item 7,9).

Finally, in consideration of the demands of task-based learning, the instrument assesses teacher's acts of support using encouragement (ATREL item 6) and continuous feedback (ATREL item 15).

\section{Data Collection \& Analytical Methods}

The Assessment of Teachers' role within E-Learning (ATREL) is completed to gather data about the participants' personal information and perception of teacher's position within elearning, that is, the role they play in the learners' task to manage their own learning and consequently be supported in various stages of active, autonomous learning.

In order to determine the students' perception of teachers' role within e-learning, analysis of means, and t-test using SPSS13 were employed. The final analysis gathered at the end of the semester (four months after the intervention) is summarized in the following sections.

In order to determine the reliability of the instrument, the analysis employs Cronbach's $\alpha$ reliability coefficient. Instrument Validity employs exploratory factor analysis, a statistical technique used to identify a relatively small number of factors that can be used to represent relationships among sets of many interrelated variables. In this study, variables include a linear combination of factors that represent actions of teachers, and student ratings of these actions can be expressed as function of factors that have impact on e-learning. Factor analysis helps identify the underlying, not-directly-observable constructs such as teachers' facilitation, mediation, and support. In this process, 49 students participated in the pilot test to validate the design of the test, which may indicate the reliability and validity.

The result shows that all the information contained in the 18 variables is kept relatively well without losing too much, and the 18 actions of the teacher can reflect the 5 roles supposed.

Table 2 reveals that the Cronbach's $\alpha$ is $0.907>0.8$, which means that the results of the test is reliable.

To sum up, the pilot study indicates that the data collected pass the tests of validity and reliability and can be used to do further analysis.

This study concerns understanding the students' perceptions of the teachers' role within e-learning, thus, it takes into account two distinct teaching settings such as the computer classroom (with internet access) and the traditional classroom (non-computer classroom). According to the site of instruction, participants received two forms of teaching which is namely, (1) e-classroom teaching (e-learning), and (2) classroom instruction (communicative instruction).

During the period of 18 weeks, e-learning participants are encouraged to have the outside-the-classroom self-study and the other group is encouraged to make active communication and interaction in the classroom using the target language.

\section{Results \& Discussion}

Aiming to explore the English teachers' role within e-learning, the present study examines the perception of both the controlled traditional group (T-group) and the experimental e-learning group (E-group) during a period of 5 months. At the start of the study, all the students surveyed are freshmen. It's presumed that their perceptions about teachers' roles were the same or both positive when they began their study at the university, and their initial perceptions were not affected by their entrance grade.

\section{Students' Perceptions of Teachers' Role}

At the end of study, data reveal that means of all actions for both e-learning group and traditional group are above 3, namely all the students still perceive teachers' performance positively. However, for some of the actions, e-learning students' perceptions are significantly different from traditional students'.

Table 1.

Case processing summary.

\begin{tabular}{cccc}
\hline & & N & \% \\
\hline \multirow{3}{*}{ Cases } & Valid & 59 & 100.0 \\
& Excluded(a) & 0 & .0 \\
& Total & 59 & 100.0 \\
\hline
\end{tabular}

${ }^{\mathrm{a}}$ Listwise deletion based on all variables in the procedure

Table 2.

Reliability statistics.

\begin{tabular}{cc}
\hline Cronbach's Alpha & N of Items \\
\hline 0.907 & 18 \\
\hline
\end{tabular}


According to the data, students believe that the presence of teachers can give them advice, offer educational and technological support and engineer various activities at all time and all places through the use of e-learning in which computer mediation is utilized. However, students consider that teachers perform equally well to provide facilitation and conduct experiments both under traditional and e-learning environments.

Obviously, the results are fairly different from the original anticipation and previous researches of many scholars, if not totally.

\section{Possible Causes of the Results}

Different factors may contribute to the results above, including physical aspect of the facilities and subjective aspect of teachers and students.

To start with, computers and LAN provided by the school are not always in good conditions. Some computers in the language lab or e-reading rooms are extremely old and often break down. The campus LAN is not always stable and sometimes one is cut off from an important connection to the internet. Another important thing is that most multimedia classrooms are not available after class.

Software for English teaching and learning is limited in quantity. The content of EFL courseware is not all satisfactory. What's more, teachers often find it hard to use a courseware to initiate interaction.

These physical factors may become obstacles for students to truly performing effective e-learning, and at the same time interfere with the implementation of teaching methods, which undoubtedly will further take its toll on students' perceptions of teachers' role under the environment of e-learning.

The negative factors stemming from teachers and students can not be neglected. Students, especially Chinese students who have been used to class lecture have not picked up the habit of autonomic learning. Many students lack the knowledge of the constructive learning, or are reluctant to change, so they remain passive receivers of the knowledge. They usually lack motivation and inclination to cooperate with the teacher and to complete the tasks assigned. This suggests that they have not changed their conception of "learning", to live up to their role of information constructor required in e-learning. And for various reasons, many of them learn rather little about the computer and network. These may lead to half-baked understanding about teachers' role. It seems that many students have not been mentally prepared to play an active part in the integration of advanced technology in their own English learning.

In addition, from students' responses to the questionnaire, it is found that most teachers involved are prepared mentally for the implementation of technology. However, some can not clarify their teaching methods and intention, which implies that many teachers have not reflected on their ways of English teaching though it is the basis for development in English teaching skills.

One more important point is that many teachers do not have enough knowledge and skills to use computers on an efficient basis. Some of them are lacking in the ability to use the internet platform and multimedia devices flexibly and some are weak in CALL theories. Such failure in technological application affects teachers to play their roles well.
Though agreeing with the teacher's new role within e-learning, many teachers still tend to teach English in a traditional way. That is to say, there is a divergence in their practice from their mental conception of their role within e-learning.

\section{Conclusion}

\section{Pedagogic Implications}

Various eloquent articles describe the features and interactive capabilities of multimedia that lend itself to integrating technology within language pedagogy (Singhal, 3.6; Sperling 25; Warschuer 125-130; Warschauer, Schetzer \& Meloni 143-140), to enhancing positive perceptions of EFL websites (Kung \& Chuo 6.1). The present study, however, shows that the students' perceptions of some of the teachers' roles remains the same within e-learning, and these roles of English teachers within e-learning is analogous to interactive foreign language teachers in the non e-learning classrooms of the earlier period (Flander 12; Yuvienco 190-219), who assumes a complex set of strategies such as, Facilitation, Advising, Conducting experiment, Engineering activities, and supporting divergent learners' productions. Evoking a multifaceted role of an interactive English teacher, these may be easily referred to as the FACES teaching strategies within e-learning. As strategies complementing each other to effectively achieve autonomy as an educational goal, they are completed freely and accordingly, not singly, nor independently of each other. These functions and competencies that constitute the complex role of an ELT within e-learning are parallel with the five roles that Simon (4) identified within distance education, which include the roles of technologist, process facilitator, content expert, instructional design, and manager. They also corroborate the teaching strategies that are helpful and necessary in guiding students in the use of Internet resources (Kung \& Chuo 6.1; Fox, 1991; Paulsen 7.3).

Nowadays, teachers' role in college English teaching has become more and more important. Teachers are the center of instruction while students are the main part of learning. Teachers must realize that they themselves are both lifelong instructors and lifelong learners. The constructivist theory has set a higher standard for college English teachers, including the demands for their knowledge, their teaching ability and classroom management. Teachers have to spend more time and energy in preparing lessons. To be good facilitators, experiment conductor, advisers, supporter, and activity engineer, teachers have also to lengthen their working hours and broaden their responsibility.

Through the study of college English teachers' role, we can find that college English teachers play an important role of facilitators to students' leaning, organizers of activities, advisers of students, supporters of students' learning styles, and experiment conductors. When teachers carry out activities in English classrooms, they should serve students and consider every detail for students. Teachers also should grasp some teaching skills of creating situation, organizing interaction, using multimedia, and so on. Meanwhile, it is necessary for teachers to be reflective practitioners. During the process of learning, teachers act as guides while students are the center. College English teachers must be aware of the orientation of teachers' role clearly, continue learning and try their best to arouse students' autonomy and improve their English level. 


\section{Limitations \& Suggestions}

The results and findings of the study clearly suggest the need for materials designed to facilitate, maintain and enhance multi-faceted teaching strategies within e-learning. They also warrant the accessibility of courses related to the fields of Psychology, Research, and Educational Technology for preservice and in-service teachers to ensure constant development among teachers. These may include, for instance, Psychologyrelated courses that offer a general understanding of the design, use and interpretation of results of Tests of Attitude and Personality allows teachers to be aware of the way the mind works, how it influences behaviour, or the influence of foreign language learners' character on their behaviour. Similarly, they may also consist of Research-related courses that provide training in the use of methods and instruments for sociological researches assists teachers to design and perform investigations in their own classrooms; also, courses on Technological Education that present teachers the opportunity to examine Information and Communication Technology-based tools for enhancing foreign language learning. These types of courses, which need to be continuously accessible and regularly improved, offer present and future teachers a know-how of applying knowledge and resources in the aforementioned fields, allowing them to effectively perform the complex roles of a facilitator, advisor, researcher, and technological and educational supporter. They function as a support for foreign language teachers who intend to provide training in the language as well as in learner autonomy and responsibility for one's own learning (Boud 17-39).

It is noteworthy that the FACES teaching strategies that enable teachers to manage the complex process of teaching a foreign language within e-learning are analogous to the teaching strategies employed within Distance Education (White 207-221). This piece of information may prove useful for investigations that intend to explore or confirm the set of teaching strategies that are appropriate and effective within Distance Education.

Candidly speaking, the present study of students' perceptions of teachers' role based on constructivism has not reached the point of satisfaction in various ways owing to the inadequacy of the author's personal understanding as well as the limitedness of relevant literature and the pressure of research time. In this study, the influence of teachers' personalities on practical teaching is overlooked for convenience thinking, which may otherwise have changed the result somehow. Moreover, students' performance in their learning could have been good proof to test the result of this study. If there will be more opportunities, further study is hoped to be conducted.

\section{Acknowledgment}

I am grateful to my academic advisor, and also my leader Yang Yanlong for his assistance and encouragement throughout the process of writing the thesis. Dr. Zhang Changzheng of School of Business Administration, Xi'an University of Technology gave me measurable help to analyze my data. In addition, I am also really appreciated Xiao Biao and Yang Pinju for munificently offering me much constructive advice, which inspired me greatly.

\section{REFERENCES}

Piaget, J. The Principles of Genetic Epistemology. New York: Basic Books, 1972.

Dewey, J. How We Think. In W.B. Kolesnick, 1958, Mentalntal Discipline in Modern Education. Madison: University of Wisconsin Press, 1933.

Vygotskv, L.S. Mind in Society: the Development of Higher Psychological Process. Boston: Harvard University Press, 1978.

Bruner, J.S. Toward a Theory of Introduction. Cambridge, Mass: Harvard University Press , 1966.

Breen, M. P. “Contemporary Paradigms in Syllabus Design.” Language Teaching 20.3 (1987): 157-174.

Willis, J. A Framework for Ttask-based Learning. London: Longman, 1996.

Brown, H. D. Teaching by principles: An interactive approach to language pedagogy. New Jersey: Prentice Hall, 1994. 115.

Zimmerman, A. L., and Evans, C. J.. Facilitation: from Discussion to Decision. East Brunswick: NJ Nichols, 1993.

Littlewood, W. Communicative Language Teaching. Beijing: Foreign Language Teaching and Research Press, 2007.

Yuvienco, Janette. "On-line-the Fast Route to Fluency: An In-process Evaluation of the Coursebook.” National Taipei College of Business Journal 5 (2003b): 190-219. 